\title{
Studies on the development of a mating disruption system to control the tomato leaf miner, Tuta absoluta Povolny (Lepidoptera: Gelechiidae)
}

5 Sandra Vacas, Cristina Alfaro, Jaime Primo and Vicente Navarro-Llopis

Centro de Ecología Química Agrícola - Instituto Agroforestal del Mediterráneo, Universidad Politécnica de Valencia, Edificio 6C, Camino de Vera s/n 46022, Valencia, Spain

Correspondence to: Sandra Vacas, Centro de Ecología Química Agrícola-Universidad

10 Politécnica de Valencia. Edificio 6C, Camino de Vera s/n 46022, Valencia, Spain. Tel: +34 963879058; Fax: +34 963879059. E-mail: sanvagon@ceqa.upv.es

Running title: Mating disruption of Tomato Leaf Miner

15 Abstract

BACKGROUND: The tomato leaf miner (Tuta absoluta Povolny) has rapidly colonized the whole Mediterranean and South-Atlantic coasts of Spain, and it has become a key problem in both outdoor and greenhouse crops. New control methods compatible with biological control are required and mating disruption appears to be a perfect method in

20 current agriculture as it is an environmentally-friendly and residue-free technique. IPM packages tested have included the use of pheromones to detect populations, but there has not been much previous research on mating disruption of T. absoluta. In this work, pheromone doses varying from 10 to $40 \mathrm{~g} \mathrm{ha}^{-1}$, emitted at a constant rate over four months, were tested in greenhouses with different levels of containment, in order to

25 evaluate the efficacy of mating disruption on T. absoluta.

RESULTS: Trials on containment level revealed that the flight of $T$. absoluta was satisfactorily disrupted with an initial pheromone dose of $30 \mathrm{~g} \mathrm{ha}^{-1}$, and levels of damage did not significantly differ from those in reference plots with insecticide treatments. Later efficacy trials confirmed our previous experiences, and release studies

30 showed that control of damage and flight disruption were taking place when releasing, at least, $85 \mathrm{mg}$ pheromone per ha per day.

CONCLUSION: Effective control using pheromone application against $T$. absoluta can be achieved, in greenhouses with high containment levels, for 4 months, with initial doses of $30 \mathrm{~g} \mathrm{ha}^{-1}$. Further research must be conducted in order to evaluate the prospect of outdoor application of mating disruption systems.

Keywords: Tuta absoluta, mating disruption, pheromone, mesoporous dispensers 


\section{INTRODUCTION}

Since the first detection in Spain of Tuta absoluta Povolny (Lepidoptera: Gelechiidae) in 2006 (Castellón, Eastern Spain), the tomato leaf miner (TLM) has invaded the whole Mediterranean and South-Atlantic coasts of the Iberian Peninsula and many other

5 interior regions of Spain. ${ }^{1}$ Due to its rapid colonization and the high levels of damage it wreaks, intervening in the control of T. absoluta has become a key issue for tomato production, both in outdoor and greenhouse crops. Being a moth of the Gelechiidae family, T. absoluta is a leaf miner that attacks tomato plants in all stages of development, damaging the stems, apices, flowers and fruits, in addition to mining the

10 leaves. $^{2}$ In high densities, TLM is able to cause significant production losses in tomato crops. ${ }^{3}$

The control of this pest requires expensive treatments with translaminar active chemicals, or the repeated application of chemicals in order to affect larvae outside the galleries. However, some investigators have proven the development of resistance to

15 some insecticides in this moth ${ }^{4-6}$ and the repeated use of the few authorized active ingredients could hasten the appearance of such resistance. It must be taken into account that, in many cases, these insecticides could also affect natural enemies, making the consolidation of biological control systems impossible. In fact, a broad variety of parasitoids and predators have been reported attacking egg, larval or pupal stages of $T$.

absoluta $^{1,2,10-13}$ Spanish tomato producers have been encouraged to control virus vector insects, such as thrips and whiteflies, by augmentative releases and conservation of beneficial insects in greenhouses, as these vector insects have become resistant to many insecticides. $^{7-9}$ Thus, alternate means of suppressing TLM populations are needed in order to prevent the deleterious side effects of repeated applications of insecticides. IPM packages could include other cultural, biotechnological and biological methods, such as 
application of entomopathogenic fungi and nematodes, ${ }^{14,15}$ and treatments with Bacillus thuringiensis, whose efficacy has already been demonstrated. ${ }^{16-19}$

Pest management tactics could also include the introduction of techniques based on pheromones. Since virgin TLM females release a sex pheromone that strongly attracts

5 males, ${ }^{20}$ efforts were directed towards identifying it. T. absoluta pheromone was characterized as $(3 E, 8 Z, 11 Z)$-tetradecatrienyl acetate (TDTA hereafter). ${ }^{21,22}$ This component represents about $90 \%$ of the volatile material found in the sex gland of calling males, but a minor component $(\sim 10 \%)$ was identified as $(3 E, 8 Z)$-tetradecadienyl acetate (TDDA). ${ }^{23,24}$ These findings permitted the development of pheromone 10 dispensers in order to test attract and kill $^{25}$ or mating disruption ${ }^{26}$ control methods against TLM. Up until now, mating disruption has been tested in South America with doses ranging from 10 to $80 \mathrm{~g} \mathrm{ha}^{-1}$, in outdoor plots of under $200 \mathrm{~m}^{2}$, without success in controlling TLM and without studies of pheromone release. Several companies have developed pheromone dispensers to detect and monitor T. absoluta populations but

15 there is only one reported experiment of mating disruption in Spain, testing doses from 0.15 to $2 \mathrm{~g} \mathrm{ha}^{-1}$, with unsuccessful results. ${ }^{27}$

Our present work shows the results of mating disruption field trials testing pheromone doses from 10 to $40 \mathrm{~g} \mathrm{ha}^{-1}$, emitted at a constant rate over four months. Mating disruption was tested in minimum-containment mesh greenhouses, as well as in highcontainment glass greenhouses. Efficacy and requirements in order for mating disruption to be successful are discussed.

\section{MATERIALS AND METHODS}

\subsection{Mesoporous pheromone dispensers}


New mesoporous pheromone dispensers were developed for the field trials carried out in the present work. All of them were formulated based on a mesoporous material, ${ }^{29,30}$ supplied by Ecologia y Protección Agrícola SL (Valencia, Spain). The dispensers were cylindrical tablets $9 \mathrm{~mm}$ in diameter, of various lengths and initial loads: 20, 60 and 80 mg (T20, T60 and T80, respectively). The formulations contained the main compound of the T. absoluta sex-pheromone 3,8,11-tetradecatrienyl acetate (TDTA), supplied by Ecologia y Protección Agrícola SL (Valencia, Spain).

The dispensers were hung inside polypropylene (PP) baskets, also supplied by Ecologia y Protección Agrícola SL (Valencia, Spain). The PP baskets were $50 \mathrm{~mm}$ wide and 90

$10 \mathrm{~mm}$ long, and the pheromone was released through a $6 \times 5 \mathrm{~mm}$ mesh. The pheromone basket had a hanger at the top to attach it to the trellis strings.

\subsection{Containment level trials}

2.2.1 Low-containment trial. An initial study was conducted to evaluate the prospects of

15 mating disruption applied to $T$. absoluta in three commercial mesh greenhouses growing tomatoes (L. sculentum, var. Valenciano), located in El Perelló (Valencia, Spain). The trial covered the whole summer cycle of the crop, from $4^{\text {th }}$ June to $26^{\text {th }}$ August 2008. Plots were arranged in two $500 \mathrm{~m}^{2}$ and one $300 \mathrm{~m}^{2}$ minimum-containment mesh greenhouses $\left(9 \times 6\right.$ threads $\left.\mathrm{cm}^{-2}\right)$ as follows: each $500 \mathrm{~m}^{2}$ greenhouse was divided,

20 with the same mesh, into two $250 \mathrm{~m}^{2}$ plots in order to apply two different pheromone doses in four separate plots: three $250 \mathrm{~m}^{2}$ plots with $10 \mathrm{~g} \mathrm{ha}^{-1}$ and the fourth to test a higher dose of $40 \mathrm{~g} \mathrm{ha}^{-1}$. To obtain the aforementioned doses per ha, two different mesoporous mating disruption dispensers were developed, with loads of $20 \mathrm{mg}$ and 80 mg TDTA (T20 and T80, respectively). Mating disruption treatment was installed following transplantation on $4^{\text {th }}$ June, together with monitoring pheromone traps. In all 
plots, pheromone dispensers were installed at a density of 500 dispensers $\mathrm{ha}^{-1}$, distributed inside the greenhouse attached to trellis strings, at a height of at least $1.8 \mathrm{~m}$. The $300 \mathrm{~m}^{2}$ mesh greenhouse was the reference plot with conventional insecticide treatments.

5 Insecticide treatments were applied in accordance with weekly assessments, when the percentage of live stages of $T$. absoluta exceeded $10 \%$. The reference plot had the conventional treatments used by the grower: Indoxacarb (Steward® Indoxacarb 30\% (Du Pont Ibérica SL, Barcelona, Spain) at $100 \mathrm{~g} \mathrm{ha}^{-1}$, applied on $25^{\text {th }} \mathrm{June}, 12^{\text {th }} \mathrm{July}$ and $1^{\text {st }}$ August) alternated with Spinosad (Spintor* 480 SC (Dow AgroSciences Ibérica,

10 Madrid, Spain) at $300 \mathrm{~g} \mathrm{ha}^{-1}$ applied on $7^{\text {th }}$ July). In view of the results, the mating disruption plots were also treated with Indoxacarb on $15^{\text {th }}$ July and $1^{\text {st }}$ August, as successful control of the pest had not been achieved.

2.2.2 High-containment trial. In a second experiment in 2009, a dose of $30 \mathrm{~g} \mathrm{ha}^{-1}$ (with T60 mesoporous dispensers, loaded with $60 \mathrm{mg}$ of TDTA) was tested in a $1000 \mathrm{~m}^{2}$

15 plastic greenhouse, property of Fundación Ruralcaja, located in Paiporta (Valencia, Spain). This was a high-containment greenhouse, which included a mesh cover $(10 \times 14$ threads $\mathrm{cm}^{-2}$ ) on ventilation windows and double doors. The crop was tomato, var. Valenciano, in hydroponic substrate, begun in January 2009. Mating disruption dispensers were applied on $4^{\text {th }}$ March 2009, at the same density and position described

20 in the low-containment trial above. The trial was conducted on the crop until $20^{\text {th }}$ July (20 weeks). Monitoring pheromone traps were placed on $19^{\text {th }}$ January to obtain population data prior to pheromone application.

A second $1000 \mathrm{~m}^{2}$ greenhouse, with the same crop and containment features as the first, was used as reference plot, using the conventional chemical control applied by the grower. Unlike the first trial, treatments with Bacillus thuringiensis Ber., var. Kurstaki; 
(Bt hereafter) at $0.13 \%$ (Costar, Syngenta Agro SA, Madrid, Spain), were applied to combat any presence of $T$. absoluta live stages, in accordance with weekly assessments. It was applied on $16^{\text {th }}$ and $30^{\text {th }}$ March, $20^{\text {th }}$ April and $8^{\text {th }}$ June 2009 in the Reference plot. In addition, Indoxacarb (100 $\left.\mathrm{g} \mathrm{ha}^{-1}\right)$ was applied when the threshold of $15-20 \%$ of 5 plants with live stages was exceeded ( $8^{\text {th }}$ May and $20^{\text {th }}$ May in the Reference plot).

\subsection{Efficacy trials}

After performing preliminary trials and having checked the influence of greenhouse containment level, two new efficacy trials were carried out in order to precisely evaluate the mating disruption technique with the T80 mesoporous dispensers.

10 2.3.1 First trial: 2009. The first efficacy trial was conducted in a high-containment greenhouse property of the company Tomspring, located in Alicante (Spain). Four plots of tomato (var. Valenciano) were arranged inside a $2600 \mathrm{~m}^{2}$ mesh greenhouse $(16 \times 10$ threads $\mathrm{cm}^{-2}$ ) with a plastic cover. Following plantation, plastic sheets were used to divide up the plots, as shown in Figure 1.

15 Pheromone treatment began on $8^{\text {th }}$ October 2009, and the trial lasted the entire crop cycle, which was 20 weeks (until February 2010). Pheromone dispensers were applied at 500 dispensers $\mathrm{ha}^{-1}$ (dose of $40 \mathrm{~g} \mathrm{ha}^{-1}$ ), with the same method and positioning as described for the previous experiments. Monitoring pheromone traps were also installed on $8^{\text {th }}$ October.

20 Chemical treatments in the Reference plot were applied in accordance with the weekly assessment of live stages of T. absoluta: one treatment with Indoxacarb $\left(100 \mathrm{~g} \mathrm{ha}^{-1}\right)$ on $13^{\text {th }}$ October, one with Etofenprox (Trebon 30 LE (Certis, Alicante, Spain) at $0.1 \%$ applied on $24^{\text {th }}$ November) and seven applications of B. thuringiensis ( $\mathrm{Bt}$ at $0.05 \%$ applied on $13^{\text {th }}$ and $27^{\text {th }}$ October, $3^{\text {rd }}, 10^{\text {th }}, 17^{\text {th }}, 24^{\text {th }}$ November, and the $22^{\text {nd }}$ December). 
2.3.2 Second trial: 2010. The mating disruption efficacy trial was performed in one $1000 \mathrm{~m}^{2}$ and three $250 \mathrm{~m}^{2}$ high-containment glasshouses. The crop was tomato, var. Valenciano in hydroponic substrate. The trial consisted of three MD plots and two reference plots, arranged as follows: the $1000 \mathrm{~m}^{2}$ glasshouse was divided by a thermal 5 blanket into two plots of $500 \mathrm{~m}^{2}$ each, in order to set up a mating disruption plot and a reference plot for conventional treatments. Two of the other three $250 \mathrm{~m}^{2}$ glasshouses were set up for mating disruption treatment, and the remaining glasshouse also acted as a reference plot. Monitoring pheromone traps were placed on $25^{\text {th }}$ January 2010, while MD pheromone dispensers were applied on $8^{\text {th }}$ February, at 500 dispensers ha ${ }^{-1}\left(40 \mathrm{~g} \mathrm{ha}^{-}\right.$

$1{ }^{1}$ ) density according to the usual method and placing. This trial covered the tomato cycle up to the harvest, which was after 23 weeks.

The $500 \mathrm{~m}^{2}$ reference plot had four $B$. thuringiensis treatments (Bt at $0.13 \%$, applied on $3^{\text {rd }}$ May, $24^{\text {th }}$ May, $26^{\text {th }}$ June and $2^{\text {nd }}$ July), in accordance with the weekly assessment of live stages. Meanwhile, the remaining plots only received the final treatment, applied on $15 \quad 2^{\text {nd }}$ July.

\subsection{Evaluation of treatment efficacy}

In all cases, in order to evaluate the efficacy of mating disruption, three commercial Delta traps, with sticky bases, supplied by Biagro SL (Valencia, Spain), were placed in each untreated or pheromone treated plot. Each trap was baited with commercial pheromone monitoring lures from Pherobank ${ }^{\mathrm{TM}}$ (Wageningen, The Netherlands). The evaluation was made by comparing the moth trap catches from the mating disruption plots with those obtained from the reference plots. Captures on sticky bases were recorded and replaced weekly, whereas the monitoring lures were replaced every 40 days. The absence of trap catches during mating disruption treatment is a good indication of the effectiveness of the technique, but crop damage assessment provides 
the final proof. ${ }^{28}$ In order to assess the percentage reduction in males captured in pheromone traps between the MD and reference plots, the mating disruption index (MDI) was calculated according to the following formula:

$$
\operatorname{MDI}=(1-(x / y)) \times 100
$$

5 where $x$ is the number of males captured in the MD plots and $y$ is the number of males captured in the control plots.

To assess crop damage, 40 plants from the central area of each plot were randomly evaluated weekly, and the number of galleries and live stages of $T$. absoluta (eggs, pupae and larvae) were recorded. Treatment efficacy results were given as a percentage

10 of plants with live stages. For efficacy trials, the percentage of damaged fruits was also recorded by revising every fruit from the 40 selected plants in the first week of harvest.

\subsection{Pheromone release profiles}

In parallel with the greenhouse trials, additional dispensers were simultaneously aged in nearby areas inside greenhouses of the same type, for 90 days in 2008, 124 days in 2009 and 164 in 2010 trial. Residual TDTA content was extracted at different ageing times. Three dispensers for ageing time were extracted by solvent-extraction, at $40^{\circ} \mathrm{C}$ during 2 $\mathrm{h}$, with magnetic agitation and dichloromethane as solvent.

TDTA content was measured by gas chromatography with flame ionization detector (GC/FID) using a Clarus®500 gas chromatograph (PerkinElmer Inc., Wellesley, USA).

20 Extracts were analyzed and quantification was made using dodecane as internal standard. All injections were made onto a ZB-5 $(30 \times 0.25 \mathrm{~mm} \times 0.25 \mathrm{~mm})$ column (Phenomenex Inc., Torrance, CA), held at $120^{\circ} \mathrm{C}$ for $2 \mathrm{~min}$ and then, raised at $20^{\circ} \mathrm{C} / \mathrm{min}^{-}$

${ }^{1}$ up to $260^{\circ} \mathrm{C}$, maintained for $3 \mathrm{~min}$. The carrier gas was helium at $1.5 \mathrm{ml} \mathrm{min}^{-1}$. The amounts of pheromone and the responses were connected by fitting a linear regression 
model, $y=\mathrm{a}+\mathrm{b} x$, where $y$ is the amount of pheromone and $x$ is the ratio between pheromone and dodecane responses.

The residual pheromone load, called $\mathrm{P}(\mu \mathrm{g})$, for each dispenser was fitted by polynomial regression. The independent variable was the number of days that dispensers had been

5 installed in the plot, which was called t (days).

\subsection{Statistical analysis}

Moth catches in pheromone baited traps, per trap and week, were analyzed using a oneway ANOVA model, followed by an LSD test $(\mathrm{P}<0.05)$, to assess the significance of differences observed in captures between treatments.

10 Contingency tables and the Pearson's chi-square $\left(\chi^{2}\right)$ test were used to test the correlations between treatments in regard to the number of damaged plants with live stages of T. absoluta. A significant chi-square statistic $(\mathrm{P}<0.05)$ is evidence for the existence of differences. Analysis was performed with SPSS 16.0.1 software (SPSS Inc., Chicago, IL).

\section{RESULTS}

\subsection{Low-containment level trial: El Perelló 2008}

Figure 2a shows population dynamics of T. absoluta, as number of moths captured per trap and day (MTD), for the different plots set up in the 2008 trial. For statistical analysis, data from weeks 1 to 5 were grouped into a single period in order to homogenize the data, together with that from weeks 9 and 10. One-way ANOVA performed with sqrt-transformed catch data showed that there were no statistical differences among catches obtained in the Reference plot and those obtained in any of the mating disruption plots $(\mathrm{F}=0.52 ; \mathrm{df}=2,53 ; \mathrm{P}=0.52)$. Therefore, none of the 
pheromone treatments (T20 and T80) had achieved a reduction in moth population in comparison with the Reference plot with chemical control, and average MDI values were around $40 \%$ during some periods.

The most important issue is the evolution of the percentage of plants with live stages

5 throughout the different assessments, which is depicted in Figure 2b. From March to June, no live stages of T. absoluta were found in any plot. Up to the beginning of July, chemical treatments were only applied to the Reference plot (indicated by black arrows in Fig. 2b), in the $3^{\text {rd }}$ July assessment it was found that around $20 \%$ and $10 \%$ of the plants in the mating disruption plots (T20 and T80, respectively) had been attacked by

10 T. absoluta. Thus, the presence of live stages had increased in the pheromone treated plots but not in the chemical Reference plot. According to the level of damage, it was decided to perform Indoxacarb treatments in all the plots, which happened on $12^{\text {th }} \mathrm{July}$ and $1^{\text {st }}$ August. The $12^{\text {th }}$ July treatment managed to restrain the increase of population as observed in the $17^{\text {th }}$ July assessment (Fig. 2b), with no significant differences between

15 treatments $\left(\chi^{2}, \mathrm{P}=0.822\right)$. However, at the end of the cycle $\left(31^{\text {st }} \mathrm{July}\right.$ assessment in Fig. 2b), the damage level in the Reference plot was significantly lower than that in the pheromone treatment plots $(\mathrm{P}=0.018)$, which means that pheromone dispensers had not achieved the disruption of $T$. absoluta population, with any of the pheromone doses tested.

\subsection{High-containment level trial: Paiporta 2009}

Before commencing MD treatment in the $6^{\text {th }}$ week, 5 and 29 moths were captured in MD and Reference plots, respectively, over 5 weeks. However, data up to $14^{\text {th }}$ week were not employed for statistical analysis, as population levels were not high enough to provide reliable information (Fig. 3a). Therefore, statistical analysis was performed with data from the $15^{\text {th }}$ to $25^{\text {th }}$ weeks, when TLM populations had increased sufficiently in 
order to detect the differences between plots, which were statistically significant in the mentioned period $(\mathrm{F}=98.89 ; \mathrm{df}=1,58 ; \mathrm{P}<0.001)$. Average catches in the Reference plot were significantly higher, which means that the pheromone dispensers installed had on this occasion a presumptive disruptive effect on the moth's flight, obtaining an average MDI of $94.4 \%$.

Regarding damage assessment, the presence of live stages of TLM in both pheromonetreated and Reference plots is shown in Figure 3b. During March no recordings of live stages were obtained in any of the plots. Damage significantly increased in the Reference plot in April, but the applications of Indoxacarb, on $8^{\text {th }}$ and $20^{\text {th }}$ March,

10 together with the application of Indoxacarb $+\mathrm{Bt}$ on $8^{\text {th }}$ June, reduced the presence of TLM. Regarding the mating disruption plot (MD), the percentage of damaged plants only exceeded 5\% at certain times and the same level of attacked plants was recorded in the Reference plot during June. Damage levels ranged from $2-5 \%$ in the MD plots during the last month without any additional chemical treatment, being significantly

15 lower in comparison with the Reference plot $(\mathrm{P}=0,006)$.

\subsection{Efficacy trial: Alicante 2009}

TLM population levels were different both during and following November $\left(9^{\text {th }}\right.$ week in Fig. 4a), so they were compared separately. Mean captures from the three MD plots differed significantly from those obtained in the Reference plot $(\mathrm{F}=34.37$; $\mathrm{d}=1,75$; $\mathrm{P}<0.001)$ up to the $9^{\text {th }}$ week (Fig. $4 a$ ), obtaining an average MDI of $84.6 \%$.

During November, the Reference plot received one treatment with Etofenprox and four with Bt. These treatments affected larval instars and achieved a population reduction in the Reference plot. As a consequence, differences between the MD and Reference plots were not so evident at the end of the cycle $\left(10^{\text {th }}\right.$ to $21^{\text {st }}$ weeks; $F=4.03 ; \mathrm{df}=1,108$; 
$\mathrm{P}=0,047)$. However, captures in MD Plots were higher than expected during the last week, which could signify the dispenser having reached the end of its lifespan.

Damage assessments showed that no live stages of $T$. absoluta were detected in the Reference plot throughout the period under study (Fig. 4b), and any presence of $T$.

5 absoluta in the MD plots was only detected after several assessments. However, live stages never exceeded the threshold of $5 \%$ presence on plants and the differences between the MD and Reference plots were not significant in any case according to $\chi^{2}$ test $(\mathrm{P}>0.05)$. No damaged fruit was observed throughout the trial in either the pheromone-treated or Reference plots.

\section{$10 \quad 3.4$ Efficacy trial: Paiporta 2010}

TLM populations were virtually zero, both in the $500 \mathrm{~m}^{2}$ and $250 \mathrm{~m}^{2}$ plots, up to the $14^{\text {th }}$ week (Fig. 5a). Twenty-one and 49 moths were captured in 14 weeks in the MD and Reference plots, respectively. From this date, statistical analysis showed that average captures obtained in MD plots differed significantly from those of Reference

15 plots $(\mathrm{F}=31.96 ; \mathrm{df}=1,148 ; \mathrm{P}<0.001)$ up to the date of harvest. Thus, a flight disruption effect was taking place in the pheromone treated plots, and the average MDI was 83.2\%. However, a changing trend was observed in all the MD plots, as captures were higher than expected during the two last weeks of the trial. This could signify the dispenser having reached the end of its lifespan.

20 The average percentage of plants with live stages of T. absoluta in the MD plots was lower than that in the Reference plots up until June. Specifically, the $26^{\text {th }}$ April assessment (Fig. 5b) showed no significant differences in the percentage of plants with live stages between the pheromone treated and reference plots $(\mathrm{P}=0.174)$. From April up until the end of May, the percentage of damaged plants did not exceed $8 \%$ in the plots with mating disruption treatments, and differed significantly from the plot with 
conventional control in the May recordings $(\mathrm{P}=0.008)$. By contrast, from mid-June to the end of the cycle, plant damage in the MD plots increased, and damage did not differ from that in the Reference plots. In the same way, at the end of the trial, an average of $1.94 \%$ of tomatoes were damaged in the Reference plots, whereas $2.89 \%$ was recorded

5 in the MD plots. The results of the July assessment would also indicate the dispenser having reached the end of its lifespan, with a consequent loss of efficacy.

\subsection{Pheromone release profiles}

Release profiles of TDTA were studied for the different dispensers tested each year. The residual pheromone load was fitted by linear regression in all cases (Fig. 6a). For T80

10 dispensers in 2008, a linear equation was obtained (eq. 1). Data at $\mathrm{t}=0$ were not fitted properly, which is explained by the higher emission rate during the first few days, until the dispenser reaches an equilibrium with the environment. So these values were disregarded, along with three outliers, resulting in a coefficient of determination of $\mathrm{R}^{2}=0.974$. Data considered outliers were disregarded according to normal probability 15 plots and residuals of regression analysis.

$$
\mathrm{P}_{\mathrm{T} 80}=59,715-0,4913 \mathrm{x}
$$

Residual pheromone load of T20 dispensers was also fitted to a linear model (eq. 2 in Fig. 6b), disregarding data at $\mathrm{t}=0$, resulting $\mathrm{R}^{2}=0.901$.

$$
\mathrm{P}_{\mathrm{T} 20}=15,275-0,1322 \mathrm{x}
$$

20 In view of the results from containment-level trials, it was decided to employ the high load dispensers with some changes in the formulation. In the case of the dispensers employed in 2009, the linear model (eq. 3 in Fig. 6c) resulted in $R^{2}=0.859$, with three discarded outliers. However, these dispensers still contained $65.8 \%$ of their initial TDTA load after 124 days of trial. 


$$
\mathrm{P}_{\mathrm{T} 60}=61,953-0,1716 \mathrm{x}
$$

Finally, for the T80 employed in 2010, it was observed that these dispensers stopped emitting after 121 days of ageing, so average pheromone contents at 143 and 164 days were the same as at 121 days (Figure 7D). Thus, these final data were discarded and

5 release profile was fitted to a linear model (eq. 4 in Fig. 6d), resulting in a coefficient of determination of $\mathrm{R}^{2}=0.915$.

$$
\mathrm{P}_{2010}=81,738-0,2427 \mathrm{x}
$$

Thus, equations 1 to 4 fitted to linear models, which means that pheromone is released at a constant rate during the period under study and mean emission rates are assumed to

10 be the value of their slopes: 491.3 and $132.2 \mu \mathrm{g} \mathrm{day}^{-1}$ for T80 and T20, respectively, in the 2008 trial, while 171.6 and $242.7 \mu \mathrm{g} \mathrm{day}^{-1}$ were the release values for T60 in 2009 and T80 in the 2009-2010 efficacy trials, respectively.

The percentage of residual pheromone load at the end of the study period must be taken into account. Dispensers T80 and T20 had residual percentages of 21.5 and $18.7 \%$ respectively. By contrast, formulations employed in 2009 and 2010 still contained more than $60 \%$ of their initial pheromone loads after 124 days, which would be a poor feature for an efficient dispenser.

\section{DISCUSSION}

20 The interruption in pheromone communication of T. absoluta in pheromone treated plots has been demonstrated by Michereff and coworkers, ${ }^{25}$ but they highlighted the need for more detailed pheromone studies to achieve a more effective mating disruption in TLM. In this previous experiment, doses up to $80 \mathrm{~g}$ a.i. $\mathrm{ha}^{-1}$ were tested, with dispensers being replaced every 4 weeks and a density of application greater than the 500 dispensers $\mathrm{ha}^{-1}$ employed in this study. Our present work contributes new efficacy 
trials for mating disruption in greenhouses applied to TLM and a new mesoporous pheromone dispenser for this purpose.

The main conclusion drawn from our containment-level trials was that mating disruption could not be achieved, with the tested pheromone doses, when a tomato crop

5 is grown outdoors or in low-containment greenhouses. Low isolation meshes or the existence of holes in greenhouse covers allow the immigration of moths from outside the pheromone-treated areas, maintaining high population densities and increasing the likelihood of casual mating. Immigration of mated females is the reason of mating disruption failures in open field environments and the need of treatments in huge areas

10 to avoid edge effect. Few studies have focused on the use of mating disruption in indoor facilities (such as greenhouses and storages), even though indoor applications provide natural boundaries that limit outdoor constraints. ${ }^{31,32}$ Nowadays, the application of outdoor mating disruption for T. absoluta is not affordable due to the need of high pheromone amounts to be applied in wide areas and its excessive cost. Currently, the

15 cost of pheromone synthesis is crucial for this technique to be applied. Commercial price of the pheromone is $900 € \mathrm{~g}^{-1}$ but this cost can be reduced to $30 € \mathrm{~g}^{-1}$ when it is synthesized at industrial scale (Ecología y Protección Agrícola SL pers. comm.). Tomato crop conducted in greenhouses allows mating disruption to be applied using lower pheromone doses in small plots.

20 In the first years of our field trials, there was not enough quantity of pheromone available to have true replicates. This was the case of Paiporta 2009 trial, where three different locations inside the same greenhouse were considered for statistical analysis. Once this preliminary test showed efficacy against TLM, and due to the big impact caused by this pest in Spain, true replicates were conducted in 2009-2010 in two different locations, Alicante and Paiporta. 
According to our results, in low-containment greenhouses, damage was not reduced in plots treated with two different pheromone doses $\left(10\right.$ and $\left.40 \mathrm{~g} \mathrm{ha}^{-1}\right)$, in comparison with a reference plot with four chemical treatments. However, when containment level increased, as in the case of Paiporta 2009 trial, damage did not significantly differ from

5 that in the reference plot with four Bt and three Indoxacarb treatments and male flight was satisfactorily disrupted with about $30 \mathrm{~g} \mathrm{ha}^{-1}$ of TDTA. Therefore, MD treatment was as effective as chemical control, with the mesoporous dispensers, for at least 4 months, when applied in greenhouses protected with a double door and a more closelywoven mesh. This would confirm the importance of the degree of containment on the

10 success of pheromone treatment on the TLM, as it prevents the migration of pests. The following efficacy trials conducted in Alicante and Paiporta, in 2009 and 2010 respectively, achieved good control of damage at the end of the cycle, what finally supported results of flight disruptions. An average MDI of $84 \%$ was obtained in Alicante when moth population peaked at the beginning of November, before Bt and

15 Etofenprox treatments were applied in the Reference plot. In Paiporta, average MDI was $83 \%$ from the $14^{\text {th }}$ week until the end of the experiment.

As stated by other authors, it is difficult to link a reduction in moth catches with an equal reduction in damage. ${ }^{33,34}$ For many moth species, it is especially difficult to obtain a relationship between male catches and plant damage. ${ }^{35}$ Regarding plant damage in our

20 present work, control of T. absoluta with MD was as effective as nine conventional treatments applied to the reference plot in Alicante, and damage was controlled in the 2010 Paiporta MD plots up to June, as observed in the $1^{\text {st }}$ July assessment (Figure $5 b$ ). Due to the high containment level of these glasshouses in Paiporta, moth migrations did not occur, so the depletion of the pheromone dispensers, reaching the end of their 25 lifespan, could be the reason for this reduction in efficacy. 
Focusing our attention on the dispensers' release profiles, in 2008, formulations T80 and T20 did not prove effective under the particular conditions of the field trial, but release profiles were fitted to linear models and residual pheromone amounts were of about 20\%. T60 in Alicante disrupted moth's flight and controlled damage for at least

5120 days, with a linear release profile, emitting an average of $171.6 \mu \mathrm{g} \mathrm{day}^{-1}$, despite having a high residual level of pheromone (65.8\% after 124 days). In 2010, T80 also had a lifespan of 4 months (121 days) with a residual pheromone load of $61.6 \%$ and an average release value of about $240 \mu \mathrm{g} \mathrm{day}^{-1}$. However, this 4 month period was not sufficient to control TLM in Paiporta 2010 up to the harvest, which is evidenced by the 10 increase in damage from June onwards (Figure 6b). Therefore, some key changes should be made to dispenser formulation to ensure the disruption of pheromone communication. The percentage of residual pheromone load must be reduced, as it is known that the pheromone synthesis is the main cost for mating disruption implementation and pheromone must not be wasted. As it has been proven that TLM

15 flight and damage could be controlled by releasing at least $170 \mu \mathrm{g} \mathrm{day}^{-1}$, the lifespan should be extended in order to achieve this level of emission for almost 6 months, to cover longer crop cycles and maintain pheromone doses of at least $30 \mathrm{~g} \mathrm{ha}^{-1}$. This value is consistent with Michereff et $\mathrm{al}^{25}$ who found interruption in male orientation in plots treated with 35 to $50 \mathrm{~g} \mathrm{ha}^{-1}$ of sex pheromone for $T$. absoluta. There are some 20 experiences on mating suppression to manage other Gelechiidae species, including Pectinophora gossypiella (Saunders), Tecia solanivora Povolny, Sitotroga cerealella (Olivier) and the tomato pinworm Keiferia lycopersicella (Walsingham). ${ }^{33,34,36,37}$ Specifically, $P$. gossypiella has been widely controlled by mating disruption in cotton fields with $78 \mathrm{~g} \mathrm{ha}^{-1}$ of gossyplure, and tests with $T$. solanivora have been successful by 25 applying $86 \mathrm{~g} \mathrm{ha}^{-1}$. 
Regarding treatment application procedure, pheromone dispensers were hung a few days after plantation in all cases, when the tomato plants were $10-15 \mathrm{~cm}$ high. With the proper formulation in the dispensers, this early application was sufficient to protect the crop throughout the season. Several authors have demonstrated that early pheromone

5 applications prevent Lepidoptera populations from increasing at mid-season, ${ }^{34,38,39}$ which can result in high-yield losses. Therefore, mating disruption of the first emerging moths is crucial in order to affect development of the subsequent generations throughout the season.

In conclusion, this study revealed that effective pheromone application against $T$.

10 absoluta can be achieved, in high containment greenhouses for 4 months, with doses of 30 g TDTA per ha employing new mesoporous dispensers. These dispensers were not replaced throughout the season and provided suitable emission rates, but formulations must be improved to avoid high residual loads and the subsequent waste of active ingredients. On the other hand, under the current conditions of pheromone synthesis and

15 the affordable pheromone doses, the application of mating disruption needs highcontainment degree greenhouses in order to succeed and be competitive with insecticide control. Therefore, research must be directed at reducing the price of pheromone synthesis and to evaluate the prospects of the outdoor application of mating disruption systems to control T. absoluta damage in outdoor tomato.

\section{ACKNOWLEDGEMENTS}

The authors would like to thank Cooperativa Agrícola del Perelló (Valencia, Spain) for providing mesh greenhouses in the 2008 trial, Carlos Baixauli and Antonio Núñez from Fundación Ruralcaja (Valencia, Spain) for providing mesh and glass-greenhouses in

25 Paiporta for 2009 and 2010 trials. Test greenhouses in Alicante were provided by 
Tomspring (Alicante, Spain), thanks to Juan Ignacio Cuerva. We also thank Mariola Breva from Tragsatec (Spain) and especially Ester Capilla for field assistance, also from Tragsatec. We are grateful to Ecologia y Protección Agrícola SL (Valencia, Spain) for

T. absoluta pheromone synthesis. Finally, we thank Frans Griepink for reviewing the 5 manuscript and James Hunt for correcting English writing.

\section{REFERENCES}

1 Urbaneja A, Montón H and Mollá O, Suitability of the tomato borer Tuta absoluta as prey for Macrolophus pygmaeus and Nesidiocoris tenuis. J Appl Entomol 133:292$296(2009)$.

2 Miranda MMM, Picanço M, Zanuncio JC and Guedes RNC, Ecological Life Table of Tuta absoluta (Meyrick) (Lepidoptera: Gelechiidae). Biocontrol Sci Techn 8:597606 (1998).

153 Picanço M, Leite GLD, Guedes RNC and Silva EA, Yield loss in trellised tomato affected by insecticidal sprays and plant spacing. Crop Prot 17:447-452 (1998).

4 Siqueira HAA, Guedes RNC and Picanco MC, Cartap resistance and synergism in populations of Tuta absoluta (Lep., Gelechiidae). J Appl Entomol 124:233-238 (2000).

205 Siqueira HAA, Guedes RNC, Fragoso DB and Magalhaes LC, Abamectin resistance and synergism in Brazilian populations of Tuta absoluta (Meyrick) (Lepidoptera: Gelechiidae). Int J Pest Manage 47:247-251 (2001).

6 Lietti MMM, Botto $\mathrm{E}$ and Alzogaray RA, Insecticide resistance in Argentine populations of Tuta absoluta (Meyrick) (Lepidoptera: Gelechiidae). Neotrop Entomol 34:113-119 (2005). 
7 van Houten YM, van Rijn PCJ, Tanigoshi LK and van Stratum PB,J., Preselection of predatory mites to improve year-round biological control of wester flower thrips in greenhouse crops. Entomol Exp Appl 74:225-234 (1995).

8 Gerling D, Alomar O and Arnó J, Biological control of Bemisia tabaci using predators and parasitoids. Crop Prot 20:779-799 (2001).

9 Blaeser P, Sengonca C and Zegula T, The potential use of different predatory bug species in the biological control of Frankliniella occidentalis (Pergande) (Thysanoptera: Thripidae). J Pest Sci 77:211-219 (2004).

10 Parra JRP and Zucchi RA, Trichogramma in Brasil: feasibility of use after twenty years of research. Neotrop Entomol 33:271-281 (2004).

11 Pratissoli D and Parra JRP, Fertility life table of Trichogramma pretiosum (Hym., Trichogrammatidae) in eggs of Tuta absoluta and Phthorimaea operculella (Lep., Gelechiidae) at different temperatures. J Appl Entomol 124:339-342 (2000).

12 Luna MG, Sanchez NE and Pereyra PC, Parasitism of Tuta absoluta (Lepidoptera, Gelechiidae) by Pseudapanteles dignus (Hymenoptera, Braconidae) under laboratory conditions. Environ Entomol 36:887-893 (2007).

13 Desneux N, Wajnberg E, Wyckhuys K, Burgio G, Arpaia S, Narváez-Vasquez C, et al, Biological invasion of European tomato crops by Tuta absoluta: ecology, geographic expansion and prospects for biological control. J Pest Sci 83:197-215 (2010).

14 Rodriguez M, Gerding M and France A, Entomopathogenic fungi isolates selection for egg control of tomato moth, Tuta absoluta Meyrick (Lepidoptera: Gelechiidae) eggs. Agric Tec 66:151-158 (2006). 
15 Batalla-Carrera L, Morton A and García-del-Pino F, Efficacy of entomopathogenic nematodes against the tomato leafminer Tuta absoluta in laboratory and greenhouse conditions. BioControl 55:523-530 (2010).

16 Giustolin TA, Vendramim JD, Alves SB, Vieira SA and Pereira RM, Susceptibility of Tuta absoluta (Meyrick) (Lep, Gelechiidae) reared on two species of Lycopersicon to Bacillus thuringiensis var. kurstaki. J Appl Entomol 125:551-556 (2001).

17 Theoduloz C, Vega A, Salazar M, Gonzalez E and Meza-Basso L, Expression of a Bacillus thuringiensis delta-endotoxin cry1 Ab gene in Bacillus subtilis and Bacillus licheniformis strains that naturally colonize the phylloplane of tomato plants (Lycopersicon esculentum, Mills). J Appl Microbiol 94:375-381 (2003).

18 Niedmann L and Meza-Basso L, Evaluation of native strains of Bacillus thuringiensis as an alternative of integrated management of the tomato leaf miner (Tuta absoluta Meyrick; Lepidoptera: Gelechiidae) in Chile. Agric Tec 66:235-246 (2006).

19 Gonzalez-Cabrera J, Mollá O, Montón H and Urbaneja A, Effect of Bacillus thuringiensis (Berliner) in controlling the tomato borer, Tuta absoluta (Meyrick) (Lepidoptera: Gelechiidae). BioControl 56:71-80 (2011).

20 Quiroz C, Utilización de trampas con hembras vírgenes de Scrobipalpula absoluta (Meyrick) (Lep., Gelechiidae) en estudios de dinámica de población. Agric Tec 38:94-97 (1978).

21 Attygalle AB, Jham GN, Svatos A, Frighetto RTS, Meinwald J, Vilela EF, et al, Microscale, Random Reduction - Application to the Characterization of (3e,8z,11z)-3,8,11-Tetradecatrienyl Acetate, a New Lepidopteran Sex-Pheromone. Tetrahedron Lett 36:5471-5474 (1995). 
22 Attygalle AB, Jham GN, Svatos A, Frighetto RTS, Ferrara FA, Vilela EF, et al, (3E,SZ,11Z)-3,8,11-tetradecatrienyl acetate, major sex pheromone component of the tomato pest Scrobipalpuloides absoluta (Lepidoptera: Gelechiidae). Bioorg Med Chem 4:305-314 (1996).

523 Griepink FC, van Beek TA, Posthumus MA, de Groot A, Hans Visser J and Voerman S, Identification of the sex pheromone of Scrobipalpula absoluta; determination of double bond positions in triple unsaturated straight chain molecules by means of dimethyl disulphide derivatization. Tetrahedron Lett 37:411-414 (1996).

1024 Svatos A, Attygalle AB, Jham GN, Frighetto RTS, Vilela EF, Saman D, et al, Sex pheromone of tomato pest Scrobipalpuloides absoluta (Lepidoptera: Gelechiidae). J Chem Ecol 22:787-800 (1996).

25 Michereff M, Vilela EF, Attygalle AB, Meinwald J, Svatos A and Jham GN, Field trapping of tomato moth, Tuta absoluta with pheromone traps. J Chem Ecol 26:875-881 (2000).

26 Michereff M, Vilela EF, Jham GN, Attygalle A, Svatos A and Meinwald J, Initial studies of mating disruption of the tomato moth, Tuta absoluta (Lepidoptera : Gelechiidae) using synthetic sex pheromone. J Braz Chem Soc 11:621-628 (2000).

27 Martí S, Muñoz M and Casagrande E, El uso de feromonas para el control de Tuta absoluta: primeras experiencias en campo. Phytoma España 217:35-40 (2010).

28 Howse PE, Pheromones and behaviour, in Insect pheromones and their use in Pest Management, ed. by Howse PE, Stevens I and Jones O, Chapman \& Hall, London, pp. 1-130 (1998). 
29 Corma A, Munoz Pallares $\mathrm{J}$ and Primo-Yufera E, Production of semiochemical emitters having a controlled emission speed which are based on inorganic molecular sieves. World Patent WO9944420 (1999).

30 Corma A, Munoz Pallares $\mathrm{J}$ and Primo-Yufera E, Emitter of semiochemical substances supported on a sepiolite, preparation process and applications. World Patent WO0002448 (2000).

31van der Pers JNC and Minks AK, A portable electroantennogram sensor for routine measurements of pheromone concentrations in greenhouses. Entomol Exp Appl 87:209-215 (1998).

1032 Ryne C, Svensson GP and Löfstedt C, Mating disruption of Plodia interpunctella in small-scale plots: effects of pheromone blend, emission rates, and population density. J Chem Ecol 27:2109-2124 (2001).

33 van Steenwyk RA and Oatman ER, Mating Disruption of Tomato Pinworm (Lepidoptera: Gelechiidae) as Measured by Pheromone Trap, Foliage, and Fruit Infestation. J Econ Entomol 76:80-84 (1983).

34 Lykouressis D, Perdikis D, Samartzis D, Fantinou A and Toutouzas S, Management of the pink bollworm Pectinophora gossypiella (Saunders) (Lepidoptera: Gelechiidae) by mating disruption in cotton fields. Crop Prot 24:177-183 (2005).

35 McNeil JN, Behavioral ecology of pheromone-mediated communication in moths and its importance in the use of pheromone traps. Ann Review Entomol 36:407-430 (1991).

36 Fadamiro HY and Baker TC, Pheromone puffs suppress mating by Plodia interpunctella and Sitotroga cerealella in an infested corn store. Entomol Exp Appl 102:239-251 (2002). 
37 Bosa F, Osorio P, Cotes AM, Bengtsson M, Witzgall P and Fukumoto T, Control de Tecia solanivora (Lepidoptera:Gelechiidae) mediante su feromona para la interrupción del apareamiento. Revista Colombiana de Entomologia 34:68-75 (2008).

538 Staten RT, Flint HM, Weddle RC, Quintero E, Zarate RE, Finnell CM, et al, Pink Bollworm (Lepidoptera: Gelechiidae): Large-Scale Field Trials with a High-Rate Gossyplure Formulation. J Econ Entomol 80:1267-1271 (1987).

39 Kehat M, Anshelevich L, Harel M and Dunkelblum E, Control of the Codling Moth (Cydia pomonella) in apple and pear orchards in Israel by mating disruption. 23:285-296 (1995). 


\section{Figure footnotes}

Figure 1. Arrangement of the different plots inside the greenhouse for the 2009 efficacy trial (Alicante, Spain). The arrow indicates the entrance of the greenhouse. Mating 5 disruption plots are referred to as 'MD1', 'MD2', 'MD3', and 'Reference' is the control plot with conventional chemical treatments.

Figure 2. Results from low-containment level trial conducted in El Perelló (Valencia, Spain) in 2008. (a) Captures of Tuta absoluta, as moths per trap and day (MTD), in

10 commercial monitoring traps for pheromone treated plots (T80 and T20) and the Reference plot. The arrow indicates the date when pheromone dispensers were applied. (b) Damage level obtained in the mentioned plots, as percentage of plants with $T$. absoluta live stages (eggs, pupae or larvae). Black arrows indicate the dates when Indoxacarb and Spinosad were applied to the Reference plot and grey arrows indicate

15 Indoxacarb applications on the pheromone treated plots.

Figure 3. Results from high- containment level trial conducted in Paiporta (Valencia, Spain) in 2009. (a) Captures of T. absoluta, as moths per trap and day (MTD), in commercial monitoring traps for the pheromone treated plot (MD) and the Reference plot with conventional chemical treatments. (b) Damage level obtained in the mentioned plots, as percentage of plants with TLM live stages (eggs, pupae or larvae). Black arrows indicate the dates when Indoxacarb treatments were applied and discontinuous arrows indicate Bacillus thuringiensis (Bt) applications, all of which in the Reference plot. 
Figure 4. Results from the efficacy trial conducted in Alicante (Spain) in 2009. (a) Average captures of $T$. absoluta, as moths per trap and day (MTD), in commercial monitoring traps for the pheromone treated plots (MD) and the Reference plot with conventional chemical treatments. (b) Damage level obtained in the mentioned plots, as 5 percentage of plants with TLM live stages (eggs, pupae or larvae). The black arrow indicates Etofenprox application in the Reference plot and discontinuous arrows indicate the dates when Bt was applied, all of which in the Reference plot.

Figure 5. Results from the efficacy trial conducted in Paiporta (Valencia, Spain) in

10 2010. (a) Average captures of T. absoluta, as moths per trap and day (MTD), in commercial monitoring traps for the pheromone treated plots (MD) and the Reference plots with conventional chemical treatments. (b) Damage level obtained in the mentioned plots, as percentage of plants with TLM live stages (eggs, pupae or larvae). Black discontinuous arrows indicate the dates when Bt was applied in the Reference 15 plot. The grey arrow indicates Bt application on the MD plots at the end of the trial.

Figure 6. Release profiles of (3E,8Z,11Z)-tetradecatrienyl acetate (TDTA), the major $T$. absoluta pheromone component, from the four dispensers employed for the different trials: (a) T80 dispenser from low-containment trial 2008, (b) T20 dispenser from low20 containment trial 2008, (c) T60 dispenser from high-containment trial 2009, (d) T80 dispenser from efficacy trials 2009-2010. Fitted lines describe the TDTA content of the dispenser (mg) versus time (number of days of ageing). 